\title{
Does Disaggregation Facilitate Our Understanding of International Regimes?
}

\author{
Review by Gabriele Spilker \\ Center for Comparative and International Studies, ETH Zurich
}

\begin{abstract}
Disaggregating International Regimes: A New Approach to Evaluation and Comparison. By Olav Schram Stokke. Cambridge, MA: MIT Press, 2012. 368 pp., \$27 paperback (ISBN-13: 9780-262-51784-3).
\end{abstract}

With his book Disaggregating International Regimes: A New Approach to Evaluation and Comparison, Olav Schram Stokke offers a fascinating contribution to the expansive field of research on regime effectiveness (Young 1999; Helm and Sprinz 2000; Miles, Underdal, Andresen, Wettestad, Skjaerseth and Carlin 2002) by suggesting a new methodological approach: the disaggregation of international regimes. In particular, Stokke argues for examining the cognitional, regulatory, and behavioral aspects of a regime separately, and for contrasting each of the three aspects to a counterfactual situation in which no regime exists. In line with increasingly popular disaggregation approaches in other fields such as the research on civil war (Cederman and Gleditsch 2009), he rightly concludes that we are only able to obtain a complete understanding of the effectiveness of a regime by employing a disaggregated perspective and evaluating these three aspects in a more nuanced fashion.

Understanding the cognitional aspect of regime effectiveness implies that the researcher evaluates whether the regime in question "entails building a shared, well-founded understanding of how best to achieve the social purpose that motivated states to create the regime" (p. 16). Hence, it implies that the regime members understand the specific nature of the problem the regime was created for to solve and how to achieve this. The regulatory part of a regime pertains to the establishment of specific rules that constrain regime members in their behavior in order to solve the problem in question. Finally, the behavioral aspect of regime effectiveness focuses on whether these rules influence members' behavior and, thus, contribute to the elimination of the problem is question. This disaggregated approach allows the researcher to draw a more nuanced picture of the effectiveness of the regime, by demonstrating which specific factors influence either some or all of the three components of regime effectiveness.

Stokke's book combines a carefully developed discussion of the disaggregation approach with an insightful empirical analysis of the Barents Sea fisheries regime. The book's thorough description of disaggregation, and its usefulness in studying regime effectiveness, as demonstrated in the step-by-step application of this methodology, is clearly the book's major contribution to the literature. Stokke offers a compelling analysis by incorporating statistical analysis, logical comparison, and process tracing, which allows him to provide an evaluation of regime effectiveness that goes beyond the typical analysis in this field.

Through its precise and detailed methodology, the book offers a detailed analysis of the effectiveness of the Barents Sea fisheries regime that serves as a great example of how to employ disaggregation. This strength of the book, however, comes along with a certain cost: analyzing only one regime implies that the 
conclusions from the analysis are to some extent limited by the choice of the regime, and the author could do more in explaining how this new approach generalizes to other regimes or what the findings of the Barents Sea fisheries regime mean for regime effectiveness more generally. The exclusive focus on one regime to illustrate the disaggregated approach could be problematic with respect to three points:

First, regarding theory, the interwoven presentation of disaggregation and the Barents Sea fisheries regime might limit the potential application of this approach. In general, there seems to be too little discussion and theorizing about the three aspects of regime effectiveness before the author applies his framework to the Barents Sea fisheries regime, and the author discusses each aspect of regime effectiveness almost exclusively in light of the Barents Sea fisheries regime. This implies that some more general lessons to be drawn from using the disaggregation approach remain unexplored. I illustrate this point with the example of the cognitional aspect of regime effectiveness. As described above, this component evaluates whether the regime in question leads its member countries to share a substantial agreement on the measures that need to be taken to achieve the goals of the regime. A difficulty with the cognitional aspect of regime effectiveness, however, is that at least some parts of this process must occur before a regime is created, otherwise, countries would lack the incentive to join the regime. Only if states acknowledge that there is some problem serious enough to be regulated and agree on an appropriate means to accomplish this, a regime will be established. Of course, the cognitional aspect of problem solving will persist after the regime has been created, since it will continuously influence member states' perceptions and their shared understanding of how to best achieve the treaty goals. That being said, there is a question of how much cognitional overlap is necessary-in other words, how much understanding states need to share-before a regime comes into being. Unfortunately, the author does not talk about this endogeneity issue, which might bias the analysis. This bias would mainly matter in cases when future member states already share a common understanding of how to solve the problem prior to the establishment of the regime. In this case, the researcher would overestimate the role of the cognitional aspect of the regime in explaining regime effectiveness if she did not control for pre-existing shared understandings.

A second reason that the study's exclusive focus on the Barents Sea regime might be problematic has to do with the specific type of problem under study. The Barents Sea fisheries regime regulates a common pool resource and has to set the incentives correctly such that the common resource in question-in this case, mainly Northeast Arctic cod-is not overused. Fishery regimes are typical examples of common pool resources and the problems attached to this are well known (Ostrom 1990). Thus, questions arise as to how well the conclusions drawn from this case may be applied to regimes dealing with other types of problems that include different incentive structures and less well-known solutions (Böhmelt and Pilster 2011).

Finally, the third issue relates to membership of the regime. The author analyzes a regime that essentially concerns only two countries: Norway and Russia. Surely, it is easier for a regime that coordinates the activities of just two states to be more effective than a regime that involves, for example, 192 state parties, as is the case of the Kyoto Protocol (Olson 1971). Hence, again the question remains of how far one can generalize the insights of this study to other regimes.

In sum, although the author could have provided a stronger theoretical foundation as well as a more detailed discussion of how his findings generalize to the study of different regimes, the proposed disaggregation approach clearly 
advances the large body of literature on regime effectiveness and will hopefully become a more standard procedure in evaluating international institutions.

\section{References}

Böhmelt, Tobias, And Ulrich Pilster. (2011) Zur Problematik kollektiven Handelns-Eine quantitative Studie internationaler Umweltregime. Zeitschrift für Internationale Beziehungen 18 (2): 63-90.

Cederman, Lars-Erik, and Kristian Gleditsch. (2009) Introduction to Special Issue on “Disaggregating Civil War.” Journal of Conflict Resolution 53 (4): 487-495.

Helm, Carsten, and Detlef Sprinz. (2000) Measuring the Effectiveness of International Environmental Regimes. Journal of Conflict Resolution 44 (5): 630-652.

Miles, Edward, Arild Underdal, Steinar Andresen, Jorgen Wettestad, Jon Birger Skjaerseth, and Elaine Carlin, Eds. (2002) Environmental Regime Effectiveness: Confronting Theory with Evidence. Cambridge, MA: MIT Press.

Olson, Mancur. (1971) The Logic of Collective Action. Cambridge, MA: Harvard University Press.

Ostrom, Elinor. (1990) Governing the Commons: The Evolution of Institutions for Collective Action. New York, NY: Cambridge University Press.

Young, Oran. (1999) The Effectiveness of International Environmental Institutions: Causal Connections and Behavioral Mechanisms. Cambridge, MA: MIT Press. 